\title{
Reengineering sustainability at Universiti Tun Hussein Onn Malaysia (UTHM): travel \& transportation
}

\author{
Wahid Razally ${ }^{1}$, Noralfishah Sulaiman ${ }^{2 *}$, Munzilah Md. Rohani ${ }^{3}$, Basil David Daniel ${ }^{4}$, Indera Syahrul Mat Radzuan ${ }^{5}$ \\ and Thuwaibah Mohd Junaid ${ }^{6}$

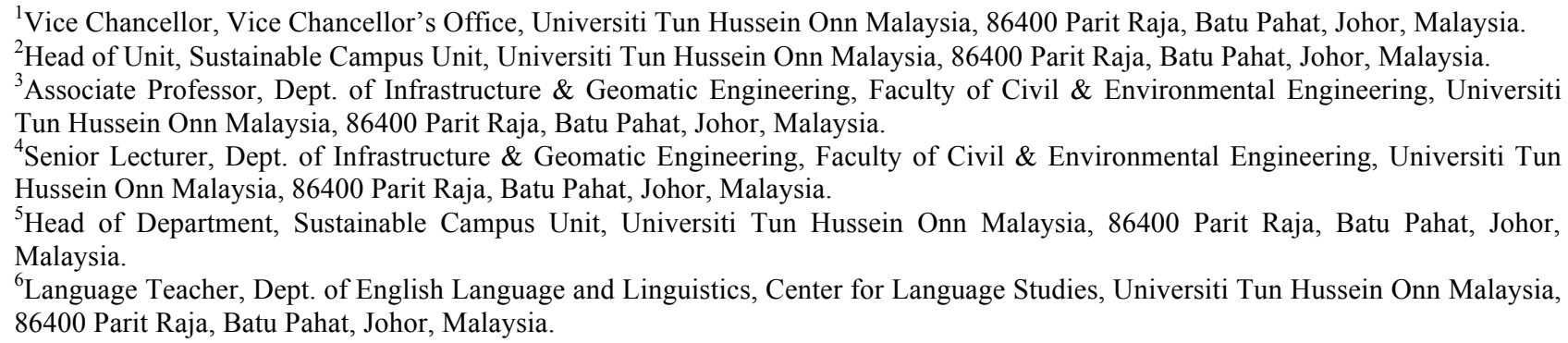

\begin{abstract}
Conveniently situated in Parit Raja town which is also known as the "Education Town" in Johor, Universiti Tun Hussien Onn Malaysia (UTHM) is a member of Malaysian Technical University Network (MTUN). In pursuit of turning UTHM as a Green Campus, UTHM has its own ambitious targets for sustainability. It is committed to provide sustainable, efficient, convenient, and safe travel and transport to all students, staffs and visitors. The inception of Sustainable Campus Unit (SCU) in May 2010, showed that UTHM has doubled its green efforts and initiatives to provide sustainable travel and transport in the campus when and where possible. The formation of Strategy in Operation (SIO5): Travel \& Transport in the SCU has encouraged active transportation and healthy commuting options in the campus by providing a wealth of innovative green transit options including bus, bicycle, pedestrian, and car. These options indeed will improve the quality of life on campus, strengthens UTHM ties to the neighbouring community, and reduces impacts on the environment as travel and transport system plays an important role on the carbon emission and pollutant level in university. This paper is therefore, trying to discuss some issues, measures and innovative strategies employed at UTHM as an integral part to achieve success in climbing the UI GreenMetric World University Ranking ladder.
\end{abstract}

\section{Introduction}

Sustainable Campus Unit (SCU) is a unit responsible for planning, developing and implementing smart and innovative sustainable solutions in the pursuit of an environmentally sustainable campus in Universiti Tun Hussein Onn Malaysia (UTHM), Johor, Malaysia. With the aphorism "Reengineering Sustainability", in February 2017, SCU has re-engineered its structure by re-branding it to become more resilient strategic entity. Ever since then, SCU has strived to continuously rethink and redesign its unique sustainable green business process in order to achieve fundamental improvements in essential measures of performance such as cost, quality of service delivery and speed of changing. Through SCU's Sustainable Champion Team (SCT), an established team consists of professional/expert individuals who seek to lead green efforts in UTHM, SCU serves as a green hub to catalyse and coordinate a large-scale university green effort towards resilient and sustainable campus ecosystem.
In SCU, there are 8 Strategy in Operation (SIO) employed to frame the process of in-campus sustainability reengineering known as SIO 1 (Corporate Governance), SIO 2 (Waste \& Recycling), SIO 3 (Energy), SIO 4 (Water), SIO 5 (Travel \& Transport), SIO 6 (Education \& Research), SIO 7 (Development, Climate \& Resiliency) and SIO 8 (Awareness, Training \& Communication).

\section{Strategy in Operation (SIO) 5: travel $\&$ transport}

\subsection{In-campus travel \& transport activities}

With more than 16,000 students and staffs, the UTHM campus is a hive of activity during the weekdays. Private vehicles (i.e. cars and motorcycles) are the primary choice of travel within the campus. The large number of vehicles in the campus is attributed to the ever-increasing student intake and the high dependency on private vehicles. As more vehicles enter the UTHM campus, the impact on environmental quality of the

\footnotetext{
*Corresponding author: nora@uthm.edu.my
} 
campus has become one of the most critical issues that calls for a comprehensive sustainable transportation system. Hence, a sustainable Travel \& Transport strategic aims are established as below:

- To promote sustainability in travel and transport options across the university;

- To encourage the use of means of transport other than private vehicles; and

- To facilitate active participation from the campus community in reducing the environmental impacts of transportation

Along with the strategic aims, the Strategy in Operation (SIO) 5: Travel \& Transport is also designed to accomplish the following objectives:

- To reduce emission of greenhouse gases from public and private vehicles in the university;

- To encourage students and staff to use public transportation as a preferred mode of travel within the campus;

- To promote non-motorised travel in the campus as a healthy and sustainable travel option among students and staffs; and

- To minimise single occupancy vehicle use and encourage ride-sharing programs in the campus.

\subsection{Promoting active transportation}

Active transportation is a term used to describe the type of travel that uses human power, i.e. walking and cycling. Also known as non-motorised transport, active transportation has many health, social and environmental benefits, such as providing basic mobility, access to public transit, affordable and sustainable transportation, and physical fitness [1].

UTHM has seen an increase in students' population over the years, resulting in great dependency on private vehicles that has caused traffic congestions, parking problems and environmental issues. Efforts are being stepped up to reduce the high numbers of private vehicles on campus, through the promotion of active transportation as a preferred choice of travel. The newly opened UTHM campus in Pagoh advocates active transportation by offering facilities for walking and cycling, while banning the entry of student-owned private vehicles.

\subsection{Creating and improving pedestrian spaces to encourage walking on campus}

Walking is undeniably the most affordable mode of transport, and the construction of walking facilities provides an elementary approach to support travel by foot [2]. Ensuring acceptable levels of walkability on campus is vital to the efficient and sustainable transportation of students and staff within the UTHM campus.

UTHM is continuously striving to create pedestrian spaces that provide clean, safe and comfortable environments suitable for walking. Efforts undertaken by the university to encourage walking include the construction of sheltered walkways, connecting walkways to bus stops and increasing the appeal of walkways.

\subsubsection{Construction of sheltered walkways}

Walkways are perceived by pedestrians as comfortable if the walkways are adequately wide, unobstructed and well-maintained. Pedestrians find walkways safe if they are segregated from roads and motorised traffic [3].

The tropical climate makes walking on campus a big challenge for students and staffs, with sweltering heat and torrential rain occurring every now and then. Sheltered walkways not only remedy this problem, but also have been found to encourage walking on campuses [4]. For better utilisation and convenience of use, UTHM has constructed sheltered walkways that form linkages between buildings on campus (Fig. 1 $3)$.

Students and staffs have found it more convenient to travel by foot since the introduction of sheltered walkways on campus, seeing as they are protected from harsh weather.

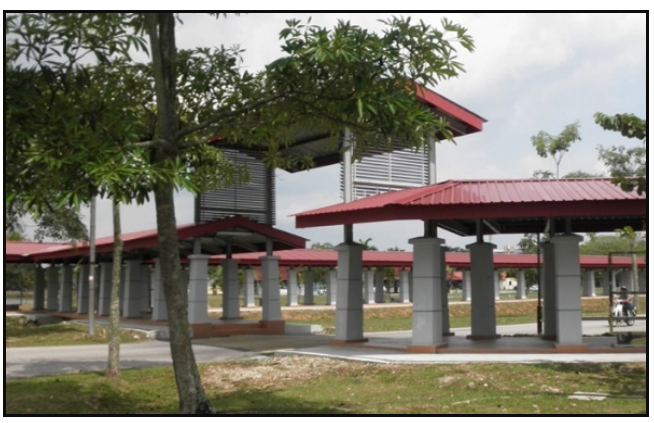

Fig. 1. Newly built sheltered walkway linking Tun Dr. Ismail Residential College to the Faculty of Mechanical and Manufacturing Engineering in the UTHM main campus.

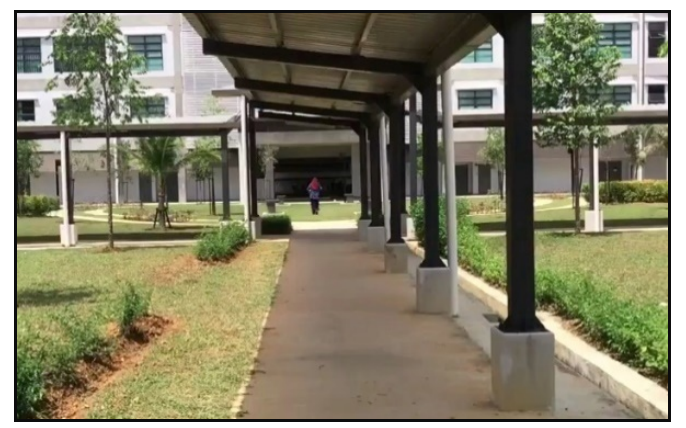

Fig. 2. A sheltered walkway built in the newly opened UTHM campus in Pagoh. 


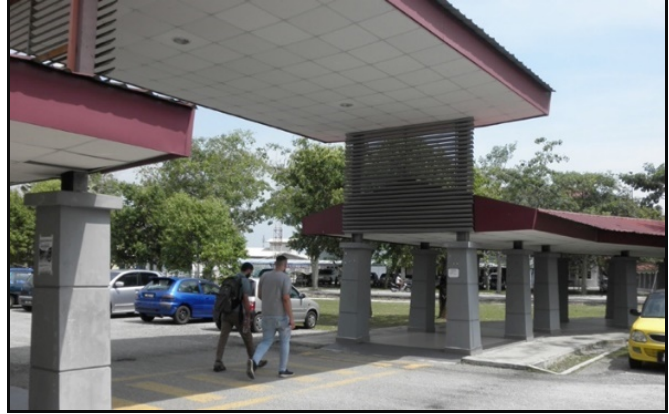

Fig. 3. One of several sheltered walkways connecting to the Lecture Complex in the UTHM main campus.

\subsubsection{Connecting walkways to bus stops}

Pedestrian facilities are vital for the support of public transportation. Facilities that are of great quality help foster the use of public transit services since transit riders are also pedestrians at each end of a trip [5].

As part of its commitment to sustainable travel, UTHM provides bus shuttle services for students within the main campus area, and to and from offcampus residential colleges. In order to encourage more students to ride the bus on campus, the university has constructed pedestrian walkways that directly link with the bus stops (Fig. 4 and 5).

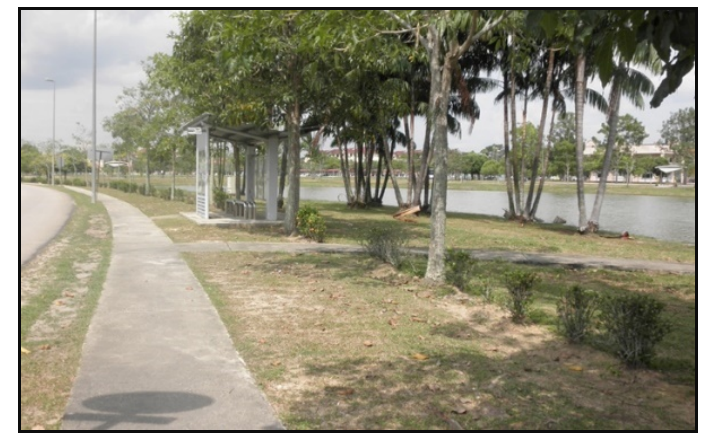

Fig. 4. Walkway linking to bus stops along Persiaran Tun Ghafar Baba in the UTHM main campus.

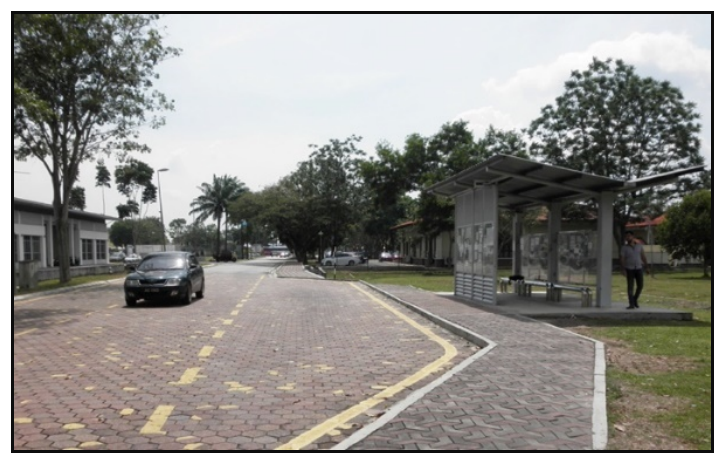

Fig. 5. Walkway linking to a bus stop along Persiaran Tun Tan Siew Sin in the UTHM main campus.

This is a key approach taken by the university to enhance pedestrian connectivity with buildings, public spaces and transit services on campus.

\subsubsection{Increasing the appeal of walkways}

Creating a walkable environment is not just about providing safe and comfortable infrastructure to support walking. The walkable environment should also be interesting, in a sense that it integrates walking routes and destinations that are lively and attractive. These added attributes result in enjoyable walking experience and help promote the culture of walking [6].

UTHM through its facilities management constantly upkeeps pedestrian walkways to ensure that they are clean and conducive for walking. Trees and plants that add aesthetic value and provide shade to walkways are regularly pruned to prevent overgrowth of foliage that may obstruct pedestrians.

Walkways have been built by lakesides to create scenic routes that allow pedestrians to enjoy nature while walking to class or taking brisk walks (Fig. 6).

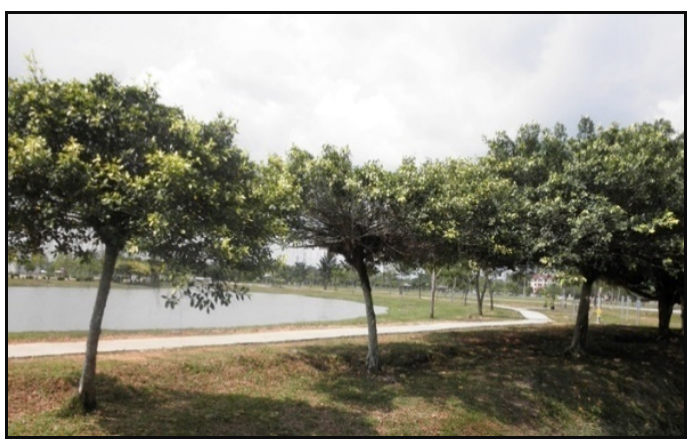

Fig. 6. Walkway by the lakeside.

The installation of outdoor exercise equipment along walkways invites more people to walk, not just as a means of travel, but for keeping fit and healthy (Fig. 7). Aesthetic enhancement of walkways has also been undertaken by UTHM. One such example is the central walkway along Persiaran Tun Ghazali Shafie, with the fitting of in-ground water fountains and attractive landscaping (Fig. 8).

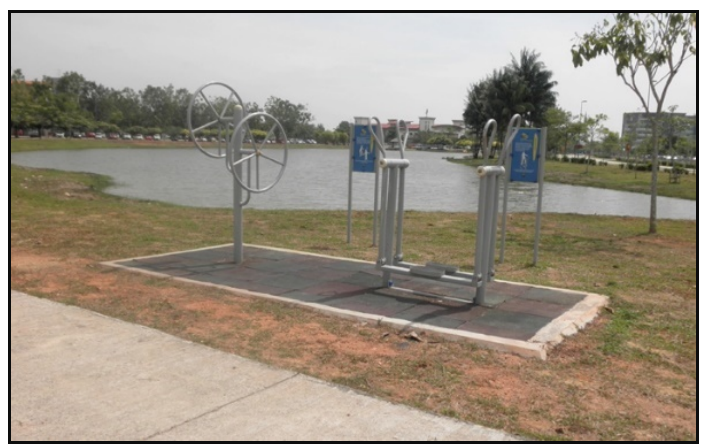

Fig. 7. Walkway with outdoor exercise equipment. 


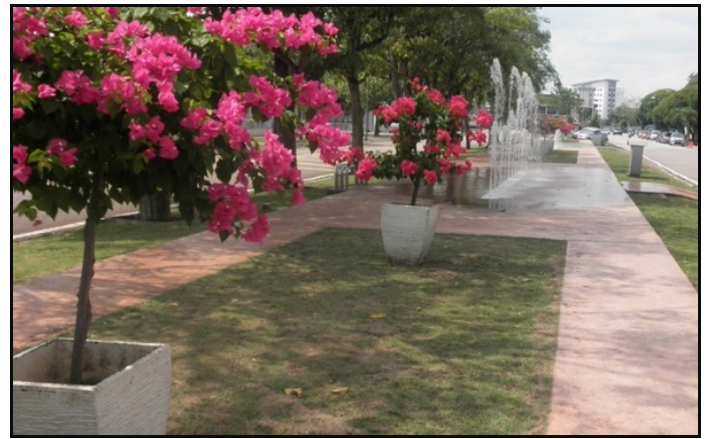

Fig. 8. Aesthetic enhancement of the walkway along Persiaran Tun Ghazali Shafie.

An ongoing park beautification project adjacent to the Sultan Ibrahim Mosque has been designed to include walkways, gazebos and benches that complement each other (Fig. 9). Studies have shown that walking in the midst of nature can relief stress [7], overcome mental fatigue [8], improve memory, and sharpen thinking and creativity [9].

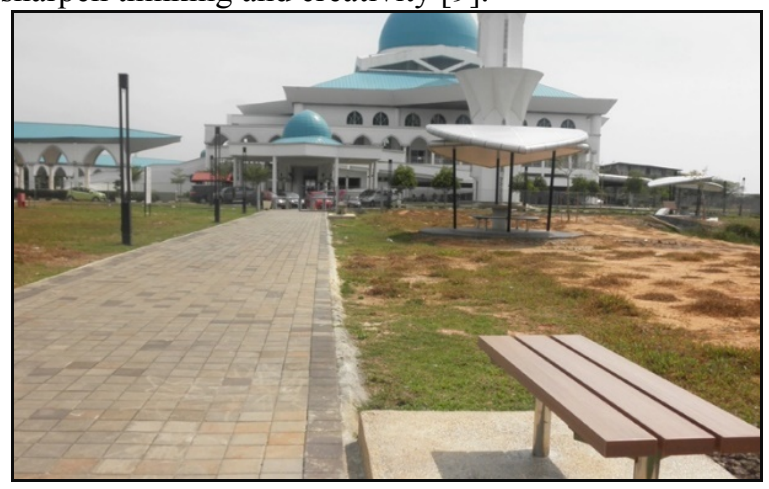

Fig. 9. Ongoing park beautification project that includes walkways, gazebos and benches.

\subsection{Encouraging active green cycling facilities}

UTHM is also implementing initiatives to encourage active green cycling transportation as a viable alternative to private vehicle and as a method of promoting a more active and healthy lifestyle. Reducing the number of motor vehicles on the campus decreases the quantity of pollutants released into the atmosphere by motor vehicles. The effects of climate change can also be reduced by encouraging drivers to use other modes of transport such as bicycle [10]. The following section discusses some of the key initiatives taken by UTHM to its newly opened branch campus, the Pagoh Edu Hub located in Muar, Johor.

\subsubsection{Providing OBike facilities}

In December 2017, UTHM completed the state-of-theart the 'oBike' green cycling facilities with a vision to move the campus community forward into an active transportation strategies and initiatives (Fig. 10). 'oBike' is a bicycle sharing services platform, allowing everyone to change how transportation is viewed locally. 'oBike' helps to decrease the traffic congestion, reduce environmental pollution, and make UTHM campus greener and a better place to study and live in. As of 15 January 2018, the total signed-up users for the 'oBike' App are 4,294 with the total bikes provided are 600 units and total trip of 16,059 (Table 1).

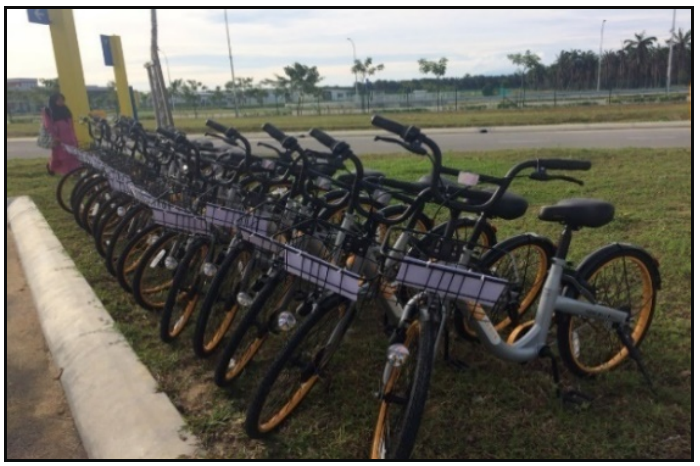

Fig. 10. The state-of-the-art the 'oBike' cycling facilities at UTHM Pagoh Edu Hub.

Table 1. OBike rides at UTHM Pagoh Edu Hub.

\begin{tabular}{|c|c|}
\hline Total Signed-up User & 4,294 \\
\hline Total Bikes Deploy & 600 bikes \\
\hline Total Trips & 16,059 \\
\hline
\end{tabular}

\subsubsection{Reducing total carbon emission}

Aside from being popular recreational activity, cycling is also efficient, affordable, environmentally-friendly and accessible means of transportation. The wider benefits of cycling include: reduce road congestion and greenhouse gas emissions; cheaper infrastructure, lower maintenance costs; road safety improvements; and lower user costs as compared to motorised vehicles [11].

UTHM Pagoh Edu Hub is currently working towards a sustainable green campus environment and this is closely monitored by the SCU. As of 15 January 2018, the distance ride of 'oBike' with $42,128 \mathrm{~km}$ indicates that good cycling infrastructure is integral to overall traffic and transport experience in the campus (Table 2). The most visible effect of the 'oBike' facilities at UTHM Pagoh Edu Hub can be seen with the reduction of the total carbon emission to $11,315 \mathrm{~kg}$. These facts clearly demonstrate the potential to increase the number of bicycle usage within the campus compound.

Table 2. OBike and carbon emission reduction.

\begin{tabular}{|c|c|}
\hline Total Distance Ride & $42,128 \mathrm{~km}$ \\
\hline $\begin{array}{c}\text { Total Carbon Emission } \\
\text { Saved }\end{array}$ & $11,315 \mathrm{~kg}$ \\
\hline
\end{tabular}




\subsection{Efficient UTHM internal bus services}

UTHM provides a unique on-campus bus ride for internal use of its students (Fig. 11). It is mainly provided to transport students from university residential areas to the main campus of UTHM. The operation of the bus is managed by Student Housing and Transportation Centre (P2P UTHM). The services are free and it is available from 0700 hours to 2300 hours daily [12]. Besides, the services also intended to minimise single occupancy vehicle use among the students and encourage ride-sharing programs in the campus.

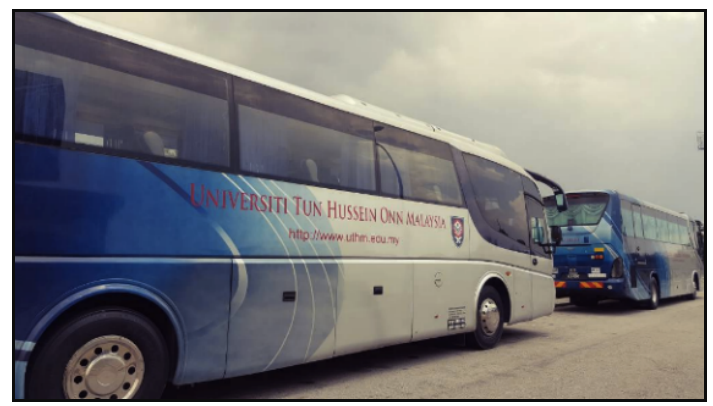

Fig. 11. UTHM on-campus bus service.

UTHM has located many bus stops adjacent to the location of students' activity centre, such as at the library, faculties and lecture hall buildings. Providing bus stops within walking distance of lecture halls or main areas where students congregate are of paramount importance for UTHM. This is to increase students' accessibility [13] and encourage more students to use the bus services as their main sources of in campus mobility. In addition, UTHM bus stop facilities are designed to suit with environment characteristics (Fig. 12) and passenger needs. This includes bus passenger shelter and seating, security (including lighting), information (timetables and maps), and pedestrian footways.

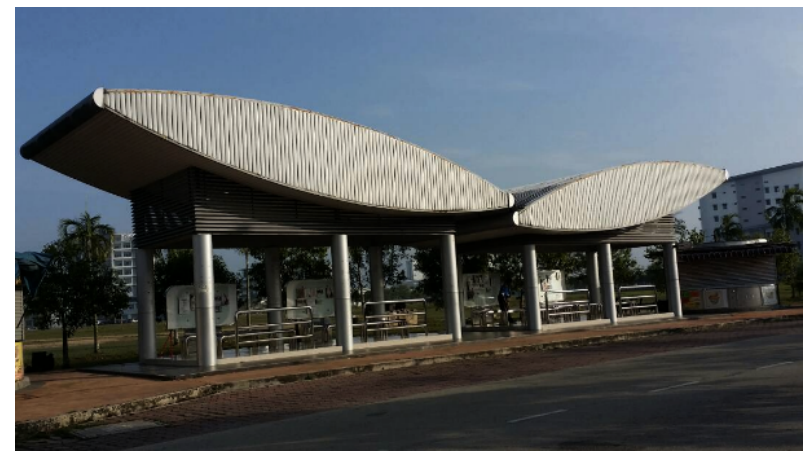

Fig. 12. UTHM bus stops are designed to suit environment characteristic and accessibility.

UTHM has taken some measures to improve internal bus services by introducing several schemes, including the introduction of UTHM-KATSANA (Fig. 13). UTHM-KATSANA is an industry-proven GPS bus tracking system \& fleet management solutions that tracks or secure vehicles, make fleet operations easier and more efficient. It is an android app that helps students to track the real time of the bus position and movement. The system is operated 24 hours and can be accessed with smart phone and internet. The system allows UTHM to monitor bus movements and makes the bus schedule accessible through UTHM website. It is proven that this service has increased students' satisfaction as the bus passengers and allows better time management among students.

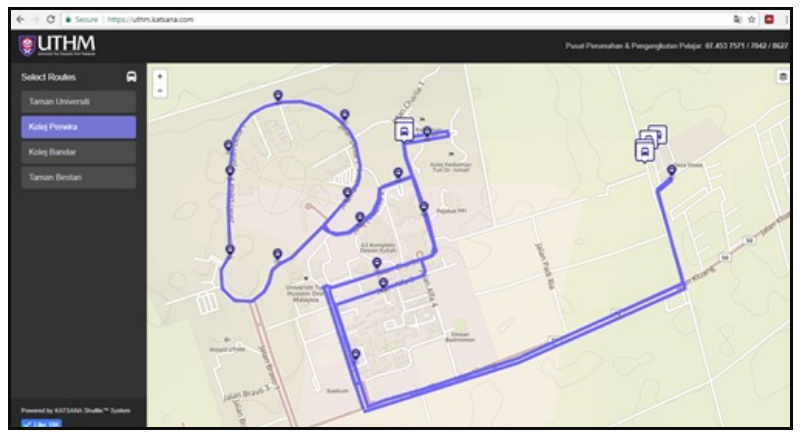

Fig. 13. UTHM KATSANA system.

Students' satisfaction is UTHM's priority. UTHM has ensured that the bus service operations have to efficiently meet daily demands of the students. Although it is reported on several cases that number of buses are not sufficient, trip frequency and bus schedule are sometimes not matched with students' time tabling and requirements, ratio of students to bus services is high and inefficient and unsafe behaviour of bus drivers, improving efficiency of the bus services operation and increasing students' satisfaction, comfort and safety are among the greatest challenges faced by Strategy in Operation (SIO) 5: Travel \& Transport team at UTHM.

\subsection{Research \& development}

To deal with the problems related to drivers' behaviour and passengers' safety, UTHM Smart Driving Research Center (SDRC) has recently conducted an innovative research study named Bus Smart DRV (Bus smart Driving Variation Indicator) (Fig. 14). Smart DRV is an in-vehicle device designed to function as an indicator for bus smart driving. The functions of the device are to display real-time driver feedback instantaneously and to warn drivers if they are any infringing limits occur while driving. It is designed specifically for Malaysian bus drivers, primarily to encourage good driving behaviour as well as for the attainment of economical and safer driving. This project is still at its initial stages and if the project succeeds, UTHM will definitely enhance the current internal bus service quality and efficiency. 


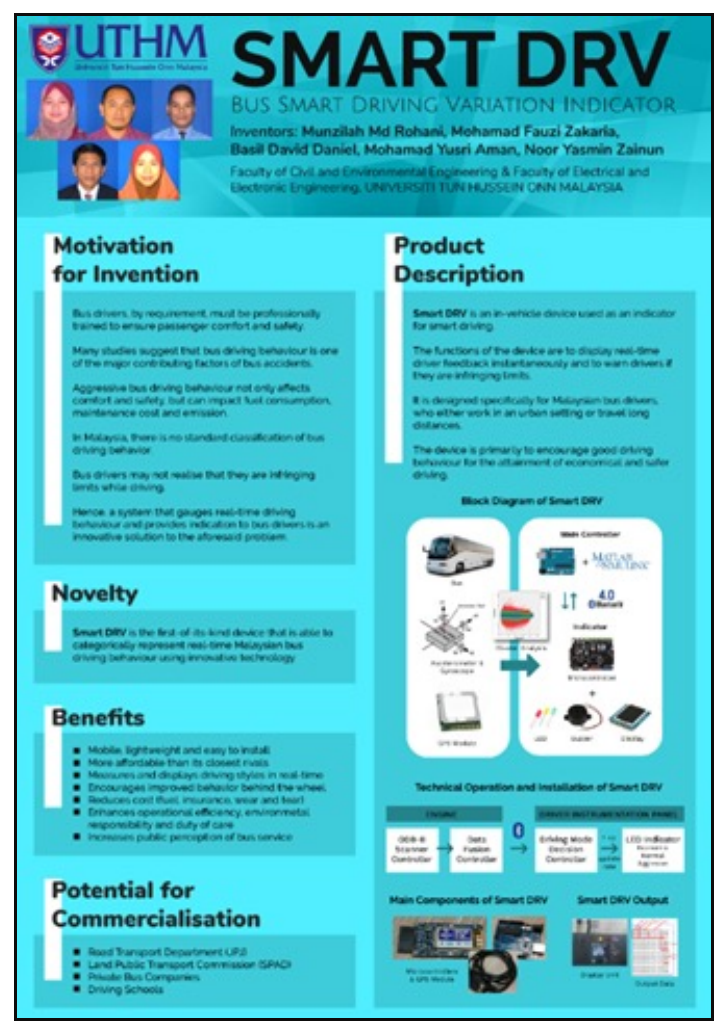

Fig. 14. UTHM Smart DRV research projects

\section{Conclusion}

The "Reengineering Sustainability" aphorism has made UTHM to focus not only on the achievement of SIO 5: Travel and Transport in UI GreenMetric World University Ranking but also for the other 7 SIOs namely SIO 1 (Corporate Governance), SIO 2 (Waste \& Recycling), SIO 3 (Energy), SIO 4 (Water), SIO 5 (Travel \& Transport), SIO 6 (Education \& Research), SIO 7 (Development, Climate \& Resiliency) and SIO 8 (Awareness, Training \& Communication). Practical, efficient and innovative green strategies are made by UTHM in order to improve the provision of SIO5 such as promoting active transportation, creating and improving pedestrian spaces, encouraging active green cycling facilities, efficient internal bus services and tackling other travel and transportation issues by conducting research and development. Many other methods are underway on campus such as improvising current travel and transport policies and guidelines, disseminating awareness through SCU's website, Facebook and Instagram, collaborating with private sectors and NGOs in promoting and encouraging sustainable travel options and activities as well as trying to reduce cost of on-campus travel and transportation innovatively.

\section{References}

1. T.Litman, Evaluating Active Transport Benefits and Costs: Guide to Valuing Walking and Cycling Improvements and Encouragement Programs, Victoria Transport Policy Institute (2017).

2. A. Frsyth, Urban Design International, What is a Walkable Place? The Walkability Debate in Urban Design, 20 (4), 274-292 (2015).

3. B.D. Daniel, S.N.M. Nor, M. Md Rohani, J. Prasetijo, M.Y. Aman, K. Ambak, MATEC Web of Conferences, Pedestrian Footpath Level of Service (FOOT-LOS) Model for Johor Bahru, 47, 03006 (2016).

4. M.Y. Merrill, P. Burkhardt-Holm, C.H. Chang, M.S. Islam, Y. Chang, Education and Sustainability: Paradigms, Policies and Practices in Asia, Routledge (2018).

5. L. Bain, B. Gray, D. Rodgers, Living Streets: Strategies for Crafting Public Space, John Wiley \& Sons (2012).

6. Victoria Walks, Developing a Walking Strategy: A Guide for Councils, Victoria Walks Inc. (2013).

7. Q. Li, Environmental Health \& Preventive Medicine, Effect of Forest Bathing Trips on Human Immune Function, 15 (1), 9-17 (2010).

8. R. Berto, Environmental Psychology, Exposure to Restorative Environments Helps Restore Attentional Capacity, 25 (3), 249-259 (2005).

9. M.G. Berman, J. Jonides, S. Kaplan, Psychological Science, The Cognitive Benefits of Interacting with Nature, 19 (12), 1207-1212 (2008).

10. Shaheen, Susan A., \& Lipman, Timothy E. Reducing Greenhouse Emissions and Fuel Consumption: Sustainable Approaches for Surface Transportation. IATSS Research, 31(1), 6-20. (2007).

11. Des McKibbin. The Wider Contribution of Cycling and Its Potential to Replace Car Journeys. Research and Information Service Research Paper: Nothern Ireland Assembly (2011).

12. Rohani, Munzilah Bus driving behaviour and fuel consumption University of Southampton, Faculty of Engineering and the Environment, Doctoral Thesis, 405pp. (2012).

13. Public Transport Team Accessible Bus Stop Design Guidance, Transport for London, Report, $51 \mathrm{pp}$ (2017) 